\title{
Staff Perceptions of implementing Project-Based Learning in Engineering Education
}

\begin{abstract}
As the introduction of active learning techniques such as project-based learning $(\mathrm{PjBL})$ becomes more widespread in engineering schools, it is important to understand the implications and development needs of staff in the transition to this mode of teaching. Through a review of education literature and a structured interview process, a set of elements that occur in the transition of staff to being a PjBL facilitator were identified. We contrast staff new to the technique with those who have been involved in this form of teaching for some time.
\end{abstract}

The study presents the key skills and approaches that are developed in staff who engage in the facilitation of $\mathrm{PjBL}$ classes to deliver engineering education. Of foremost importance was the responsiveness of staff to be confident in supporting students' learning in an active learning environment where the student assumes much of the control.

Keywords: Problem-Based Learning, Faculty Development.

\section{Introduction}

Over the past two decades, a procession of reports have called for change in engineering education or levelled criticism at the current processes for the development of future engineers (Spinks, Silburn and Birchall 2006; Rauhut 2007; Perkins 2013; Morgan and Ion, 2014). These reports all highlighted skills gaps in graduates entering the professional workforce. Throughout, there is a reoccurring desire for engineering graduates with not only technical skills, but also with a wider range of transferable skills and an understanding of the societal context of engineering. In the US, a significant voice for change in engineering education has been led by Boeing (McMasters 2004). These reports all extol a focus on the sociological and economic aspects of engineering, communication and presentation skills, legal and ethical aspects, as well as the importance of teamwork and leadership skills. 
In response, several initiatives have arisen which redefine the undergraduate engineering curriculum and introduce active learning techniques. Project- and Problembased Learning has been explored by many with cited benefits including enhanced problem-solving skills, creativity and criticality, which are aligned with vocational/professional demands. For example, see the CDIO (Conceiving — Designing — Implementing - Operating) programme (Crawley et al. 2007) or the Aalborg model of problem-based learning (Kolmos 2002). These educational frameworks give the student the opportunity to put into practice their technical and theoretical knowledge while at the same time enhancing a wide range of professional skills and also broadening their understanding of the societal context in which their solutions will operate. Despite these high-profile developments, it has been observed that "these changes...have not resulted in major systemic change within engineering education" (NSF 2008, 4). A number of researchers have highlighted the importance of the role of the teacher and the need to work towards a student-focused strategy whereby interest is focused on helping students change their conceptions of what they are studying (Trigwell, Prosser and Waterhouse 1999) and how the experience of staff is a critical component in the development of new approaches to engineering education (Arlett, Lamb, Dales, Willis and Hurdle 2010; Kolmos, Du, Dahms, and Qvist, 2008). This suggests that one possibility for the lack of change may lie in the different pedagogical approach and the positioning of student-centred learning within active learning especially in the role of the lecturer in facilitating student learning and supporting independent group-work rather than transmitting knowledge.

Given these concerns, this research explores the perceptions of new and experienced staff in the delivery of PjBL to understand more fully the challenges and barriers associated with this approach to teaching and learning. 
We aim to identify how staff adapt to PjBL in the context of their own teaching. Critical to this will be the prior experiences of both new and more experienced staff, their concepts of what the education process they are engaged in should aim to achieve and how interpersonal relationships are formed and function.

In this work we specifically use the term project-based learning (PjBL), although we recognise that there is often some confusion over the exact definition and its relationship to Problem-Based Learning (PBL). Following the distinction set out by Donnelly and Fitzmaurice (2005) we identify the majority of the activities described within this work as $\mathrm{PjBL}$ due to the extended time period (typically one-week to fiveweeks), and the presence of some structure involving milestones, developed by the instructor, towards a product of some sort. Although we are drawn to the framing of Hanney and Savin-Baden (2013) we resist the use of the term project-led PBL in this work.

\section{Literature Review}

Pedagogically, PjBL is situated within a constructivist learning environment (Savory and Duffy, 1995), where in contrast to didactic approaches, lecturers take on the role of facilitator. This role, as highlighted by Dennick and Exley (2004) and Barrows (1986), is pivotal to the success of $\mathrm{PjBL}$ since inappropriate and insensitive interventions can cause facilitation sessions to go off track. Many tutors find this type of interaction with students at least unusual and at worst challenging (Azer 2005). In part, this is related to an individual's journey to becoming an active learning facilitator. For example, SavinBaden and Major (2004) describe the apparent contradictions that staff may exhibit between their acceptance of more constructivist philosophies of knowledge generation that they embrace within their research and transmissive models that dominate their 
teaching practice.

One concern is the shift of the position of power that $\mathrm{PjBL}$ requires. Students are not led towards what the facilitator considers to be the 'right' answer but instead are given space to find this route, or in the case of more open-ended problems, potentially be able to find a route that the facilitator had not even considered. This suggests a shift in the relationship between the student and facilitator from a traditional role as 'gatekeeper' to a role which can often be closer to the role of 'fellow-traveller' (Jones 2005). It is also acknowledged that a single strategy is often not sufficient, but that the type of interaction may have a complex, dynamic structure (Light and Cox 2009). It requires the facilitator to understand the different phases of group work and adapt their style of support accordingly, with the overall aim of providing sufficient support while encouraging independence. As observed by Hmelo-Silver and Barrows $(2006,24)$ "the facilitator must continually monitor the discussion, selecting and implementing appropriate strategies as needed".

Within engineering, Zhou and Valero $(2016,149)$ have drawn attention to the promotion of creativity in students' projects and the need for supervisors to be "aware of the complex relationships between student, teacher and task and the student response". The social dimensions of the facilitator-student interaction are a key part of fostering the student-student development needed to produce group independence (Light and Cox 2009).

Another area of debate centres on the specialist knowledge requirement of the facilitator. Schmidt (1994) stated that a higher level of subject matter expertise of the tutor related to higher achievement from the students. While this has been interpreted to suggest detailed knowledge of the problem at hand, Schmidt does not give a detailed 
definition of 'subject-expertise'. It is plausible that this could be interpreted as proof of the value of broad disciplinary knowledge over more generalist facilitatory experience. This fits well with the assertion of Norman (1988) that problem-solving is not a generic skill or strategy which can be learned in isolation, but a function of experiential knowledge of similar situations. Therefore, although in-depth knowledge of the specific problem at hand, even to the extent of having investigated solutions in detail before the start of the process might not be necessary, a broad experience of problem-solving within the context of the problem is clearly beneficial. The shift from transmission to that of educational support described above, as well as the easy access to facts and 'knowledge' online, suggest that the ability to provide technical insight is at least matched by the need to provide support to the more process-oriented elements of the problem-solving process (Poritz and Rees 2016). As identified by Azer $(2005,676)$ "Group facilitation is about process rather than content."

Unsurprisingly there have been various attempts to identify approaches to facilitation (Heron 1989). Wilkie (2004) suggests four approaches: Liberating Supporter, characterised by minimal interventions, Directive Conventionalist, who maintain control of both material and method, Nurturing socializer, who demonstrate a studentcentred approach aiming to socialize students into 'good' practice and Pragmatic enabler, typically developed by more experienced facilitators and encompassing a number of different styles to meet different students' needs. What is problematic here is that while approaches to facilitation are helpful in giving a language to define different facilitation styles, they do not necessarily help to define the stages of development of a facilitator and hence how tutors/lecturers trained in more didactic approaches develop their expertise as a $\mathrm{PjBL}$ facilitator. 
Of interest, is the work of Hmelo-Silver and Barrows (2006), who considered the goals and strategies of an experienced facilitator through observations of their interaction with a group of students during two PBL sessions. Three important areas emerged. Firstly, that the expert facilitator used a number of different strategies in their facilitation to help support the critical thinking of the group. Typically, this involved questioning that directed the students' owning thinking. Secondly, that these strategies evolved over time, with scaffolding being removed as students progressed and took more responsibility for their own learning. Finally, that the methods of facilitation were strongly linked to the learning goals, which went beyond the specific problem set. This supports the view of Azer (2005) who emphasises activities that promote the functioning of the group, for example, setting ground rules, promoting a positive group dynamic and defining group roles (including that of the staff member) more than seen in the study of Hmelo-Silver and Barrows (2006).

Kaufman and Homes (1996) observed that students most appreciated the group facilitation skills of the tutor, valuing a friendly nature and enthusiasm above clinical knowledge. This enthusiasm and approachability may come from a number of areas. For some staff it may be a natural way for them to approach teaching, however, it is also likely to have its origins in their view of the value of this type of activity and its relationship to their own professional values, for example if they had spent time as professional practicing engineer. Savin-Baden (2003) argues that the tutor's pedagogical stance, i.e. the way they see themselves as teacher and the way that students see themselves as learners, is of critical importance to successful learning in the PBL environment. It is suggested that this stance is formed by the tutor's prior experiences and notions of teaching and learning. The stance taken by the tutor will heavily influence the type of facilitation provided and hence the type of experience 
received by the students as well as the way students react to the tutor. It is also important that staff recognise their own pedagogical stance and the prejudices and styles that it brings. The developments and transitions noted above suggest that training and staff development might well be necessary to enable some, if not most staff to develop into effective PjBL tutors.

\section{Methodology}

This study took place in an Engineering Faculty that had been implementing a curriculum development programme which included the introduction of $\mathrm{PjBL}$ activities across the first two years of several undergraduate engineering programmes (Mitchell, Nyamapfene, Roach and Tilley 2019). Staff involved in the delivery of the PjBL activities were interviewed between February and March 2016. In line with the constructivist principles that underpin pedagogic approaches to $\mathrm{PjBL}$, the methodology was framed within a constructivist approach as a way of exploring staff perceptions and experience in relation to the phenomenon being studied (Creswell 2003; Merriam and Tisdell, 2015). From this perspective, emphasis was placed on understanding human experiences in which participants are active in constructing meaning as they engage in the world they are interpreting. By involving staff who were either experienced or new to delivering PjBL, it was hoped that comparative analysis between these groups would contribute new understandings of how staff, with different prior experiences, perceive and implement PjBL. All staff interviewed had been engaged in the one-week scenarios that were central to the programmes (Mitchell, Nyamapfene, Roach and Tilley 2019) although, as became apparent, within this set of activities there were still variations between the style of these projects, in particular concerning how structured or openended the tasks set were. 


\section{Interview Design}

The study used semi-structured interviews to allow a flexible approach that gave coverage of a set of key questions but allowed scope to follow up on participant responses in depth to fully understand their perceptions and experiences of implementing PjBL (King and Horrocks, 2010; Patton, 2002; Robson and McCartan 2016). The question set was developed in response to areas identified in the literature review and from professional experience. Questions covered three areas. Prior Experience, covered analysis of prior learning and staff perceptions of approaches to teaching; Experience of active learning, where the focus was on the participant's behaviour in relation to their engagement with this teaching style and Instructor Skills focused on the emotional response to $\mathrm{PjBL}$ teaching, personal development and the challenges faced by staff in adapting to $\mathrm{PjBL}$ facilitation. The question set is provided in Appendix 1.

\section{Participants}

Through purposive sampling eight staff were identified to be part of the study, based on their level of experience of implementing and/or delivering PBL to undergraduate students. This included a mix of staff, in terms of age, length of experience of PjBL and gender. The participants were five men and three women. Each interviewee was categorised as either newcomer or experienced based on an assessment of their description of their prior experience of PjBL-like group work in a higher education setting prior to becoming involved in the introduction of the programmes at UCL. Five of the participants were classified as 'experienced', identified by pseudonyms as Albert $(M)$, Brian $(M)$, Clive $(M)$, Deidre $(F)$ and Elsie $(F)$ and three 'newcomers', identified as Xavier (M), Yvonne $(F)$ and Zander $(M)$. 


\section{Analysis}

The method of data analysis was inductive, thematic analysis. Given that thematic analysis is not linked to a particular theoretical approach (Spencer et al., 2014), it provided a way of exploring the data for themes in a way that was consistent with the constructivist approach taken in the research (Braun and Clarke, 2008). This involved looking for patterns and the meaning of what was being said (Spencer et al., 2014; Patton, 2002). This iterative process of analysis (Mabry, 2008) was guided by the phases recommended by Braun and Clarke (2008).

Firstly, to allow for familiarisation with the data, all interviews were transcribed and read several times. This familiarization stage was important to ensure maximum understanding of the emerging themes (Howitt and Cramer, 2014). Secondly, an initial set of codes were developed where interviews where treated as a single data set. Within each transcript, initial notes were made against each section to start the process of identifying specific activities or comments which seemed relevant to the research question being studied. Having extracted excerpts associated with each code, this third phase grouped codes into possible themes. The aim was to produce a thematic 'map' relating as many codes as possible from phase two.

The fourth phase of the analysis reviewed the map produced to develop a smaller number of key groupings within a core theme and a set of sub-themes allowing the construction of a thematic network. Once this network emerged, all prior stages were re-evaluated to ensure that the themes that had resulted adequately reflected the original data. The final phase of analysis used the thematic network as a basis to 'generate meaning' from the data captured. Comparative analysis between experienced and newer staff was used as a tool to identify differences in approach between these two groups. 


\section{Study Limitations}

It should be recognised that this study considers only a small sample size of eight practitioners, all from a single institution (although across multiple departments). This particular study could be deemed to be a 'typical', rather than an 'atypical' case study (Mabry, 2008), as there are likely other universities working in similar contexts, sharing similar profiles, that could use this study to gain insight into their own situation. The methodology of data collection followed privileges the opinions and perceptions of the participants of the study.

\section{Findings and Discussion}

Following the process outlined above five key themes emerged: prior teaching and learning experience that may shape the participant's experience and their grounding in engineering, perception of teaching and style, depth of structure and planning of teaching activities and confidence and communications. This section presents the comparative analysis for each of these sections in turn.

\section{Prior teaching and learning experience}

Only one of the participants described having themselves experienced an undergraduate programme consisting of $\mathrm{PjBL}$ activities:

[My course] was very hands on. So, every year we did a design or a project. [The design projects] were really engaging as we always had an audience. (Deirdre)

Other than this there were no striking elements of participants' backgrounds that would suggest that they were any more likely to be engaged in project-based learning activities than any other member of staff. A stronger connecting feature was seen in their expressed appreciation for the benefits to students of authentic learning especially given 
the vocational nature of an engineering degree.

I thought that obviously you are trying to create an environment which they might face when they operate as engineers which is a positive thing to do. (Xavier)

Given their practice and experience as engineers, this seems an obvious link, inherently associated with a consideration of the nature of being an engineer.

\footnotetext{
A lot of [our students] will go on to be engineers so incorporating problem-based learning seems a no brainer. (Elsie)

Scenarios were new to me. I think it is a great idea, especially for engineering. During my time studying at universities we were taught some theories but could not put it in context. (Zander)
}

Engineering education at university is often accused of forgetting this link, instead retreating to engineering science in its purest form and therefore de-emphasising the applied nature of engineering (Rugarcia et al. 2000). What seems to connect all the respondents is a conviction that as part of an education, students must engage in problem solving. The framing that staff involved are able to give to the problems set to students is one facet of the pedagogical stance defined by Savin-Baden (2003) as critical to the success of PBL.

\section{Grounded in Engineering}

Staff wishing to develop activities that enhance both students' theoretical knowledge and their skills in problem-solving, communication, team-work and design seemed naturally drawn towards the use of authentic, project-based engineering activities as a vehicle to best develop these skills. These types of experiences are hard to create within a lecture theatre, must be developed early, and must be in context if accusations of 'addons' are to be avoided. Therefore, it is also only natural that PjBL should be highly 
regarded with its focus on problems that are engaging and authentic, drawn from professional life (Barrett, Cashman and Moore 2011). Participants talked of keeping the context and content current and creating an authentic, situated learning environment for students. This could be achieved in different ways, from the subject matter of the problem:

It was always a matter of, every scenario week is designed to be completely contemporary. It's not some historic case study. Here is a current issue. (Albert)

to the structure of the activities that students were required to engage in:

We liked the idea of getting the student to think about using evidence and collecting evidence and interpreting the information they had collected and using that to inform their design instead of just picking an idea out of the air and using that as their design. (Elsie)

and trying to create an authentic learning environment for the students:

The design review meeting, that meeting would typically happen between the director and a team or the team and a client. (Deirdre)

[Bringing in a real client] really grounded the scenario and got the students thinking about the importance about getting the design right for that client. (Yvonne)

There was evidence of staff struggling to think of the context in which to situate the learning. There is a trade-off between problems that enthuse and those that promote either skills development and /or knowledge acquisition required. As Savin-Baden and Major $(2004,69)$ point out there are a range of different problem types that can be deployed depending on the desired outcomes acknowledging that "problem design is complex and multi-faceted issue about which there are relatively few straightforward answers". 
The most difficult thing was figuring out a theme, a context in which to do it [a project-based learning scenario]. (Elsie)

Most respondents had gravitated towards more project-based learning styles of activities, noting the blurring of the distinction in a field such as Engineering as observed by Hanney and Savin-Baden (2013). In Schmidt and Moust's Taxonomy (2000) this would generally class the problems as a mix of fact-finding and strategy problems as many typically start with periods of research but then lead on to the application of that research to design or solution. Staff spoke of the ability to produce a real artefact of some sort as the output of the project as a key benefit:

I think it's the fact that they actually get to produce something at the end of the day. So, they see that the design and the maths that they did actually matches the results at the end. (Brian)

\section{Teaching and Learning Styles}

In his discussion of the facilitator, Barrows $(1992,12)$ states "Tutoring is a teaching skill central to problem-based, self-directed learning”. It has therefore been concluded that the enactment of students' thinking or reasoning skills should be within the context of an environment where the student is encouraged to manage the process as much as is possible, balanced with the fact that "without appropriate and sensitive interventions, the PBL session could go off track" (Dennick and Exley 2004, 88). This suggests a facilitator must decide when to stand off and allow students to take ownership of their work, but they must still be prepared to make carefully timed intervention/s as required. This view was supported by the respondents, although each seems to have developed their own strategies in their role as facilitator. 
I sort of lead the activities but not really telling the students how to engage with them, rather some general guidance. (Clive)

I'm very much about facilitating learning and enabling students to teach themselves. (Yvonne)

More experienced facilitators adopted strategies in line with Wilkie's (2004) notion of the pragmatic enabler, while newcomers and some experienced staff described how their first interactions had predominantly been of the Directive Conventionalist type.

My personality does have a tad of control freakary in it. I just wanted it to go smoothly, so if I try to control it, it is more likely to happen as I want, but that's not the case. (Elsie)

Respondents also discussed the role that a Nurturing Socializer can play and the balance that needs to be struck when applying this approach.

A lot of it is helping them figure out how to research the problem to start with and start conceptualising. (Xavier)

They also commented on the adaptive nature of facilitation:

deliberately spent time with each group, if they wanted me or not, to say "how is it going?", "what is your initial plan?", "hang on is that a good idea?". (Yvonne)

Barrows (1992) suggests that to be effective, facilitators should operate at a metacognitive level and avoid expressing opinions. As identified by the participants, to do this, staff must move from a practice of giving information to posing probing questions, a technique often advocated in small group teaching situations (Dennick and Exley 2004). Participants spoke of returning and deflecting questions, suggesting alternatives and using reflection. The insights into facilitation strategy, especially those 
of experienced staff echo the work of Azer (2005) and Hmelo-Silver and Barrow (2006).

The idea is not to tell them the answer but ask the right questions that lead them in the right direction. (Albert)

[My facilitation style is being] outside the circle, prompting them with questions to help them go beyond their thinking. (Deidre)

With less experienced staff there was some evidence that the range of strategies to interact with the students were less broad or not applied with such confidence:

I can give them what I think my problems are with it and hope that they follow the thread of my logic and that might encourage them to think a bit more critically about their solution to the problem. (Xaiver)

Van Hattum-Janssen and Vasconcelos (2008) identified six areas that students felt were important when they evaluated tutor performance (Knowledge; Attitude; Project progress; Critical thinking-problem solving; Team functioning; Individual learning). Interestingly, their study suggests that students are most concerned with the tutor's knowledge of procedural aspects of the programme, such as their knowledge of project approaches and organisation and their attitude towards the work, over their indepth knowledge of the subject. These findings reflect some of the evidence from experienced staff in this study, where it is clear they are less worried about their knowledge in the specific area of the project, but more concerned with setting up the problem correctly and enthusing the students. This is in line with the results of student surveys performed by Kaufman and Holmes (1996) which suggested students place greater value on process over content.

De Grave, Dolmans and Van Der Vleuten (1999) found that tutors who focused students on the acquisition of expert knowledge were deemed (marginally) less effective 
than those who prejudiced the learning process. It is also interesting to note that their study concludes that the level of experience of the staff does not always equate to student satisfaction. Although, this could equally be because experienced staff, as highlighted in the findings here, have more of a propensity to challenge students, while less experienced staff acknowledged a tendency to give answers. As suggested by Williams and Ceci (1997), challenging approaches may not win favour among students in typical end-of-course evaluations. We should also consider that the level of experience of the students involved may have an effect on these results.

\section{Structure and Planning}

Different elements emerged in the discussion of how staff addressed the issues of structuring their PjBL activities. Although, these could be viewed as procedural aspects, they demonstrated much about the attitudes of staff towards the activities. Critical to all staff was understanding the prior knowledge and experience of the students within the group. In contrast to didactic-type lectures, in PjBL staff perceived themselves as partners in the students' learning process and in so doing, they gained an insight into the strengths, weaknesses and prior knowledge of the student group in a way that they are unlikely to achieve in a lecture-based environment.

In the first year, I wasn't sure what [the students'] capabilities were. So, that's why I provided a lot more instruction. (Elsie)

Both experienced and newcomer staff re-aligned their teaching based on better understanding of the background knowledge and capabilities of the students. As one newcomer reflected:

[I was] basically handing them what I thought the answer should be rather than listening to them and thinking about what their opinion is on it. (Xavier) 
The same member of staff spoke about his own development and how he had identified the limitations of this approach and discovered a much more effective strategy.

If you can listen to them and think about what their rationale or opinion about the design is or whatever, just give it a gentle nudge rather than trampling all over it. (Xavier)

All participants maintained that some aspects of preparation were of vital importance, but this differed according to experience. For new staff, logistics and practicalities played a central role coupled with a desire to have in-depth knowledge of the problem at hand. Those with more experience tended to acknowledge the logistical imperatives without them dominating their thinking. They also played down the indepth knowledge, perhaps having conducted some preliminarily testing of the project to ensure its feasibility, but instead relying on their own engineering problem solving experience to be able to be one-step-ahead of students and so still act as a guide. For example, one experienced staff member advised:

If you are setting one up from scratch then I typically have at least attempted the full thing, not always, but I would have a pretty good idea of a route from the scenario to a solution. (Brian)

However, it was also important to avoid getting too focused on the solution to the problem, and prejudicing this over the process that the activity is aiming to teach:

Do you need to prepare to run a scenario like that? No. If you are an engineer, that should be how you work every day. It shouldn't require a great deal of thought. (Brian)

There is clearly some divergent thinking between newcomer and experienced staff with regards to the level of technical preparation required. The more experienced staff tended to prefer flexibility, whereas less-experienced staff often looked to have a 
good idea of the solution to the problem. This level of insight into the solution raises the concern that students might be led towards what the facilitator considered to be the 'right' answer.

Experienced staff relied on a lower level of structure, giving much more control over to the students. This had evolved over time, with staff reflecting on past practice and stripping away levels of structure that at best were seen as unnecessary, but that at worst, either confused or infuriated students. What remained were a set of tightly focused check-points, well aligned with the learning outcomes of the task as a whole. These check-points were opportunities for rich staff engagement and constructive feedback. The general structures revolved around these sessions, with most of the adhoc support that remained viewed more as reassurance to the students and intelligence gathering to assist in interventions later. It was also suggested that it has an impact on the way staff interact with the groups as evidenced by Elsie's reflections on her first experience of $\mathrm{PjBL}$, describing a disconnect between the way we think of the problem and the way students experience it:

We're not 18 and just out of school.... We tried to organise them and that is where all the problems arose. (Elsie)

As a response, she progressed from a highly structured to far more flexible approaches:

It is less structured for them time wise, so they can choose when they turn up and do their experiments, less structured than initially..... That was definitely the problem in the first year, less the 2nd year and now it's fine. Actually, there is not that much structure now. (Elsie)

This requires a level of confidence from staff to rely on less preparation but instead to follow the assertion of Norman (1988) that problem-solving is not a generic skill or strategy which can be learned in isolation, but a function of experiential knowledge of 
similar situations.

There were differences, too, in views as to where the main focus of the learning outcomes should be. Some more experienced members of staff perceived that focusing on learning outcomes, particularly technical learning outcomes, was key. Other staff had started to value the problem-solving process more and had shifted their focus away from the technical side to emphasise the development of transferable skills. While these viewpoints may seem at first sight contradictory, it is more likely that they are an artefact of the different implementations of PjBL seen across the participants in the study. Hence, in a spectrum of implementations (Savin-Baden and Major 2004), these viewpoints fit to problems at different points and therefore, are highly reliant on the context of the desired learning outcomes.

Some staff used PjBL activities as a consolidation exercise, giving students the opportunity to pull together strands of knowledge from taught classes and make new understanding and connections. In this mode, the transferable skills are often explicitly valued. Although technical skills are also being advanced this is much more individual to each student, with each group and even each group member creating their own new knowledge based on their previous experiences. When using PjBL as a more enquirybased instruction technique, staff expected the students to develop specific and predetermined technical skills through the course of their interaction with the problem topic. This is closer to the usual interpretation of PBL. Here, the acquisition of a specific technical skill or command of a new technique will be privileged as the learning outcome. Transferable skills will still be important as the vehicle by which the skill is acquired and by which its mastery will be demonstrated however, they will be secondary to the core technical competence. 
There are the things we want you to do by the end, so you have to work out how to get to that end point. (Clive)

We absolutely have to get right, in writing the assessment criteria, so they get what we want out of the scenarios. (Elsie)

What was occasionally evident, was that some of these learning outcomes were implied and assumed as the desired direction rather than being explicitly stated. Some interviewees provided evidence of being able to generalise this approach and apply it flexibly to different circumstances, while others had a more fixed view. This may be an additional cause for confusion if staff assume, when they talk about PjBL, that they are all considering the same thing, when in fact the different context and aspirations have resulted in subtly different interpretation of PjBL. In the context of developing an effective community of practice it is important that these assumptions are exposed and interrogated as it will be through this process that others may both adapt their practice but also see how PjBL can be applied flexibly depending on the context of the desired learning outcomes.

\section{Confidence and Communications}

It was apparent that the introduction of active learning techniques pushed some staff out of their traditional comfort zone. Allied to this was a clear sense that a key attitude in the implementation of PjBL was confidence. Participants spoke of the exposed nature of their new role and how it required self-confidence to step out from behind the lectern that is often at odds with their experience of academics from their prior learning. In particular, it was the open and disparate nature of the questions generated by the openended problems that challenged staff most. As Dennick and Exley $(2004,89)$ suggest "Facilitators have to be prepared to expose their own ignorance and be prepared to say 
'I don't know"'. It was felt that being put in this position is much more likely to happen in a PjBL environment and although shocking at first, can be a situation that staff formulate strategies to deal with. This ability to be more integrated in the students' discussions, stepping away from being the authority figure, also marks a transition to a fellow-traveller (Jones 2005) or pragmatic enabler (Wilkie 2004) role.

You can be wrong, or you cannot know the answer. That can be a scary thing for someone who is just starting teaching that you cannot have all the answers. (Xavier)

Despite these concerns, it is clear that most participants now actively enjoy this more interactive and student-centred style of learning. Interestingly some respondents noted that they felt some of their colleagues would not be suitable for this style of teaching, in particular their ability to cope with the interactive style and the demands to build a relationship with a cohort of students as part of a learning partnership.

If you're not comfortable with groups as facilitator or lecturer, then you might have an issue, but I think dealing with the team experience and the students that don't believe in it or aren't engaging or too engaged, or too forthcoming for the way the team dynamics are, that's definitely something you have to deal with. (Albert)

Changes in the overall structure of the programme can make staff uncomfortable and require confidence. The issue of control also deserves mention since this is in contrast to traditional modes of teaching. Van Hattum-Janssen (2012), for example, described the challenges staff faced when moving from a traditional mode of teaching where a teacher is typically responsible for the whole programme and able to exert full control to a project-orientated approach where elements of control must be given up. This can happen in two ways; through giving control to students and sharing control with other staff. 
I think it [the main issue faced] was trying to project manage the students. It was a ridiculous thing to try and do. That is basically what was difficult. Actually, it was something that they found difficult too. They were a bit pissed off that I was saying, you lot are finished you have to get out and you lot have to start. (Elsie)

There is clearly a level of confidence needed to build a more active relationship with the learners, this can be tested even further when the relationship between learners within a group becomes strained. This was highlighted by many as a worry in their facilitation skills. We see that there can be a number of different causes for tension within groups, all of which can potentially be challenging for staff but that might need to be dealt with in different ways.

We've had our fair share of team dynamic issues where some of the individuals do not engage or contribute or there are personality issues, and trying to help those teams overcome those issues, can be quite, you know, involve quite a lot effort. (Albert)

A core concern for many with all group work is the issue of the "social loafers" (Pieterse and Thompson 2010), those students that contribute little to the team, with the typical worry that their presence will lead to decreased motivation among the active team members (Cheng and Warren 2000). This has led some staff to investigate peer assessment techniques (Roach, Smith, Tilley, Marie and Mitchell 2017), while others take the view that this will be to the detriment of the "passengers" learning and hence their lack of engagement will create its own penalty. Although likely to be true, there is undoubted still an impact on those that do engage which needs to be considered and mitigated wherever possible.

Many of the teaching activities described by respondents were not single person enterprises but required collaboration in a teaching-team with other staff. Certainly, within the context of this study, team-teaching of this nature was not common outside of 
these $\mathrm{PjBL}$ modules. This is a powerful change but also one that staff do not all automatically and instantly adapt to. Although somewhat of a generalisation, it is a widely accepted stereotype of academic endeavour as being a highly individualistic activity, whether it be teaching or research. The challenge facing staff is not only to work in a teaching-team to deliver the PjBL programme, but also to support the interpersonal skills of others to support the successful functioning of student teams.

\section{Conclusions}

This study has considered the key perceptions of staff involved in the facilitation of $\mathrm{PjBL}$ in an engineering faculty. Analysis of the interview data has demonstrated that confidence was a key feature of staff engaged in delivering PjBL activities. In particular, staff must be able to be confident in developing interpersonal relationships with student groups as a means of supporting their learning process. Participants found supporting fractious or dysfunctional groups as the most challenging responsibility of a PjBL facilitator. More experienced staff had developed some strategies to deal with such issues, but still commented on the pressure that this placed them under.

Staff also struggled with confidence in accepting the role as a collaborator in the learning process rather than a figure of authority or knowledge. Staff identified that their key functions are to guide teams through the use of probing questions. They also acknowledged the need to be willing to step in, when deemed necessary, to 'nudge' teams in the right direction to move to the next stage, while also providing functional advice on matters such as process and procedure

These skills manifest themselves as a set of strategies to deal with events that occurred during the course of the problem and the facilitation class. Linking to the issue of confidence in supporting groups and group-work, staff had developed strategies to deal with conflict and help groups work together however, these were less well formed. 
It was recognised that the landscape of a PjBL class is a complex and uncertain one, certainly when compared to a traditional lecture class. The issue of this complexity is exacerbated by the transfer of control to students within the process. Less experienced staff either tended to try to impose greater structure on proceedings to regain some of this control or concentrated on making sure that some of the more logistical and practical elements of the class were developed. As staff gained more experience, they became more relaxed about the level of structure and this shift of control, but also took the logistical elements more in their stride and were able to adopt less structured approaches to the activities. This allowed them to focus on a smaller and simplified set of key learning outcomes. Again, this, in fact, comes down to confidence as much as acquired skill.

One area where the literature highlighted apparently conflicting views concerned the level of technical skill required to provide successful facilitation. In keeping with this disjuncture, differing views emerged within the participants despite some common underlying trends. Some of the more experienced staff, viewing their role as fellowtravellers, considered that a basic check of the feasibility of the problem being set was all that was necessary. Others, in a similar mode to their less experienced colleagues still favoured rather more rigorous trialling of possible solutions before the outset of the problem. Although, this may demonstrate their attitude towards the structure of the programme, it may also be symptomatic of the different types of problems and projects developed across the faculty.

This work has highlighted the transition that staff make as they become more skilled and proficient in designing and delivering $\mathrm{PjBL}$ activities. It should be noted that this is a process of continuous improvement. There is no suggestion that the initial PjBL activities designed by inexperienced staff are ineffective however, it is clearly seen that, 
as experience is gained, improvements are made. Most notably, staff streamline their activities providing a more focused experience for both staff and students.

The perceptions outlined in this paper should provide inspiration for those designing training and instruction to new staff embarking on facilitation roles. It has highlighted that any training must provide an immersive experience, where confidence can be developed in, what is for many, an unfamiliar style of teaching. Our response has been to form communities of practice where experienced and less experienced staff can work together and be supported to be able to deliver a successful PjBL experience.

\section{Acknowledgements}

The authors would like to thank all the staff who gave their time to be interviewed for this study. We would also like to thank Prof Dilly Fung and Dr Inês Direito for their feedback on this manuscript.

\section{Disclosure statement}

No potential conflict of interest was reported by the authors. 


\section{Appendix 1}

\section{Interview Questions}

- How would you characterise the way you were taught at university?

- Can you describe for me your main forms of teaching you been involved in prior to being involved in the IEP?

- What were your pre-conceptions of the teaching on the challenges/scenarios? (For those without prior experience)

- How would you describe the practice of teaching on a challenge/scenario?

- Can you describe for me types of activity are most important in class?

- What activities did the students engage in most strongly?

- What skills do you feel you developed, if any, as part of teaching this course?

- What skills do you feel would better prepare you for teaching on these modules?

- Can you describe for me was the most challenging element of the course for you to facilitate?

- Has this experience change your view of how you might teach in future? 


\section{References}

Arlett, C.J., F. Lamb, R. Dales, L. Willis and E. Hurdle, 2010, "Meeting the needs of industry: the drivers for change in engineering education." Engineering Education 2010: Inspiring the next generation of engineers, Aston University, EE2010 Conference Proceedings, Loughborough: Higher Education Academy Engineering Subject Centre, Loughborough University.

Azer, S.A., 2005 Challenges facing PBL tutors: 12 tips for successful group facilitation, Medical Teacher, 27(8), 676-681.

Barrett, T., D. Cashman, and S. Moore. 2011. Designing problems and triggers in different media. in New approaches to problem-based learning revitalising your practice in higher education, Abingdon: Routledge.

Barrows, H.S. 1986. “A taxonomy of problem-based learning methods.” Medical Education, 20(6): 481-486.

Barrows, H.S. 1992 The tutorial process. Springfield, Il: Southern Illinois University Medical School.

Braun, V. and V. Clarke, 2008. 'Using thematic analysis in psychology.' Qualitative Research in Psychology, 3, 77-101.

Cheng, W. and M. Warren. 2000. "Making a difference: Using peers to assess individual students' contributions to a group project." Teaching in Higher Education, 5(2): 243-255.

Crawley, E., J. Malmqvist, S. Ostlund, and D. Brodeur. 2007 Rethinking Engineering Education: The CDIO Approach, Berlin: Springer Press.

Creswell J.W., 2003. Research design: Qualitative, quantitative, and mixed methods approaches, 2nd ed. Thousand Oaks, CA: Sage.

De Grave, W.S., D.H. Dolmans, and C.P. Van Der Vleuten. 1999. "Profiles of effective tutors in problem-based learning: scaffolding student learning." Medical Education, 33(12): 901-906.

Dennick, R., and K. Exley. 2004 Small group teaching: Tutorials, seminars and beyond, Abingdon: Routledge.

Donnelly, R. and M. Fitzmaurice, 2005 "Collaborative Project-based Learning and Problem-based Learning in Higher Education: a Consideration of Tutor and Student Role in Learner-Focused Strategies”. In G. O'Neill, S. Moore \& B. 
McMullin (eds) Emerging Issues in the Practice of University Learning and Teaching (pp.87-98). Dublin, AISHE/HEA.

Hanney, R. and M. Savin-Baden. 2013. "The problem of projects: understanding the theoretical underpinnings of project-led PBL." London Review of Education, 11(1): 7-19.

Heron, J. 1989 The facilitator's handbook., London: Kogan Page.

Hmelo-Silver, C.E. and H.S. Barrows. 2006. "Goals and strategies of a problem-based learning facilitator." Interdisciplinary Journal of Problem-based Learning, 1(1): 21-39.

Howitt, D., and D. Cramer. 2011 Introduction to Research Methods in Psychology. New York: Pearson.

Jones, G. 2005 Gatekeepers, Midwives and Fellow Travellers: Learning Alignments and Pedagogy in Adult Education. London: Mary Ward Centre

Kaufman, D. M. and D.B. Holmes. 1996. "Tutoring in Problem-based Learning: Perceptions of Teachers and Students." Medical Education, 30(5): 371-377.

King, N. and C. Horrocks, 2010. "An introduction to interview data analysis." Interviews in qualitative research. London, Sage.

Kolmos, A., 2002. "Facilitating change to a problem-based model." The International Journal for Academic Development, 7 (1): 63-74.

Kolmos, A., X.Y. Du, M. Dahms, and P. Qvist. 2008. Staff development for change to problem-based learning. International Journal of Engineering Education, 24(4), pp.772-782.

Light, G. and R. Cox. 2009. Facilitating: Small Group teaching, in Learning and Teaching in Higher Education, London: Sage.

Mabry, L. 2008. “Case Study in Social Research.” In The Sage Handbook of Social Research Methods, edited by P. Alasuutari, L. Bickman, and J. Brannen, 328343. London: Sage.

McMasters, J.H., 2004 “Influencing Engineering Education: One (Aerospace) Industry Perspective.” International Journal of Engineering Education, 20(3): 353-371.

Merriam, S. B. and E. J. Tisdell, 2015. Qualitative research: A guide to design and implementation. New Jersey: John Wiley \& Sons. 
Mitchell, J. E., A.Z. Nyamapfene, K. Roach, E. Tilley, 2019. "Faculty wide curriculum reform: the integrated engineering programme." European Journal of Engineering Education.

Morgan R., and S. Ion. 2014. The Universe of Engineering: A Call to Action, London: Royal Academy of Engineering.

NSF - National Science Foundation. 2008. Innovations in engineering education, curriculum, and infrastructure (IEECI) (NSF 08-542). Arlington, VA.

Norman, G.R., 1988. "Problem-solving, solving problems and problem-based learning." Medical Education, 22(4): 279-286.

Patton, M. Q. 2002. “Two decades of developments in qualitative inquiry: A personal, experiential perspective." Qualitative social work, 1(3), 261-283.

Perkins, J. 2013 Professor John Perkins' Review of Engineering Skills, London: UK Department of Business Innovation and Skills.

Pieterse, V. and L. Thompson. 2010. "Academic alignment to reduce the presence of 'social loafers' and 'diligent isolates' in student teams". Assessment \& Evaluation in Higher Education, 15(4): 355-367.

Poritz, J. A., \& Rees, J. (2016). Education is not an app: the future of university teaching in the internet age. Routledge.

Rauhut, B. 2007 Educating Engineers for the 21st Century, London: Royal Academy of Engineering.

Roach, K., M.S. Smith, E. Tilley, J. Marie, J.E Mitchell. 2017 "How student-generated peer-assessment rubrics use affective criteria to evaluate teamwork." Paper presented at the Annual Conference of the European Society for Engineering Education (SEFI), Angra do Heroísmo, Portugal, September 18-21.

Robson, C., and K. McCartan, 2016. Real World Research. John Wiley \& Sons.

Rugarcia, A., R.M. Felder. D.R. Woods, and J.E. Stice, 2000. "The future of engineering education I. A vision for a new century". Chemical Engineering Education, 34(1): 16-25.

Savery, J.R., and T.M. Duffy. 1995 "Problem based learning: An instructional model and its constructivist framework", Educational technology 35(5): 31-38.

Savin-Baden, M. 2003. Facilitating problem-based learning. New York: McGraw-Hill Education. 
Savin-Baden, M., and C.H. Major. 2004. Foundations of Problem-Based Learning. Society for Research into Higher Education and Open University Press.

Schmidt, H.G. 1994. "Resolving inconsistencies in tutor expertise research: does lack of structure cause students to seek tutor guidance?". Academic Medicine, 69(8): 656-662.

Schmidt, H.G., and J.H.C. Moust. 2000 “Towards a Taxonomy of Problems Used in Problem-Based Learning Curricula", Journal on Excellence in College Teaching, 11(2/3): 57-72

Spencer, L., J. Ritchie, R. Ormston, W. O’Connor and M. Barnard, M. 2014 'Analysis: principles and processes', in Ritchie, J., Lewis, J., McNaughton-Nicholls, C. and Ormston, R., Qualitative Research Practice, 267-293, London: Sage Publications Ltd.

Spinks, N., N. Silburn, and D. Birchall. 2006 Educating Engineers for the 21 st Century: The Industry View, London: The Royal Academy of Engineering

Trigwell, K., M. Prosser, F. and Waterhouse, 1999. "Relations between teachers' approaches to teaching and students' approaches to learning”. Higher education, 37(1), pp.57-70.

Van Hattum-Janssen, N., and R. Vasconcelos. 2008. “The tutor in project-led education: evaluation of tutor performance." Paper presented at the $36^{\text {th }}$ Annual Conference of the European Society for Engineering Education (SEFI). Aalborg, July 2-5.

Van Hattum-Janssen, N. 2012. "The role of Teachers in Projects”. In Project approaches to learning in engineering education: The practice of teamwork, edited by Luiz Carlos de Campos, Ely Anotonio Tadeu Dirani, Ana Lucia Manrique and Natascha Van Hattum-Janssen. 161-187. Springer Science \& Business Media.

Wilkie, K. 2004. “Becoming Facilitative: Shifts in Lectures' Approaches to Facilitating Problem-Based Learning." In Challenging Research in Problem-based Learning, edited by Savin-Baden, M. and K. Wilkie, K., 81-92 London: Open University Press.

Williams, W.M., and S.J. Ceci. 1997 ““How'm I doing?” Problems with student ratings of instructors and courses". Change: the magazine of higher learning 29(5): 1223. 
Zhou, C., and P. Valero. 2016. "A Comparison of Creativity in Project Groups in Science and Engineering Education in Denmark and China." In Multidisciplinary Contributions to the Science of Creative Thinking, edited by Giovanni Emanuele Corazza and Sergio Agnoli, 133-154 London: Springer. 